\title{
Discussing cardiopulmonary resuscitation with patients and relatives
}

\author{
Kevin Stewart
}

\begin{abstract}
Summary
This paper aims to give clear guidance for doctors working in the UK about their responsibilities when discussing cardiopulmonary resuscitation with patients and their relatives. The ethical and legal framework for making decisions is outlined and the commonly encountered dilemas are discussed.
\end{abstract}

Keywords: resuscitation, communication, ethics

\begin{tabular}{|l|}
\hline $\begin{array}{l}\text { Ethical principles } \\
\text { governing resuscitation } \\
\text { decisions }\end{array}$ \\
\hline - respect for patient autonomy \\
- beneficence \\
- non-maleficence \\
- justice
\end{tabular}

Box 1

Newham General Hospital, London E13 8RU, UK

K Stewart

Correspondence to Dr K Stewart, Royal Hampshire County Hospital, Romsey Road, Winchester SO22 5DG, UK

Accepted 26 April 1995
In the UK there is confusion about how much patients and relatives should be involved in decisions about cardiopulmonary resuscitation (CPR).$^{1-10}$ This paper aims to give precise guidelines for doctors working in general hospitals in the UK, based on ethical and legal principles, which will help them identify:

- when they are obliged to obtain patients' consent before making Do Not Resuscitate (DNR) decisions,

- when they can make DNR decisions without consent,

- when to involve patients' relatives in discussions,

- what information they should give to patients,

- what to do if there are disagreements with patients or relatives,

- how this might change in the future.

\section{Background}

In the US policies have existed for many years which require doctors to obtain patients' consent before making DNR decisions. ${ }^{11}$ If patients are unable to participate in decisions then there is legal provision for relatives to act on their behalf. These policies emphasise respect for patient autonomy in medical decision-making, although there is evidence that American doctors do not always practice in accordance with them. ${ }^{11}$

In the UK many hospitals did not have written resuscitation policies until recently ${ }^{3}$; the traditional view was that these were unnecessary, since British patients were more likely to trust their doctors to decide on their behalf. ${ }^{12}$ Consultants usually made decisions without informing patients, to save them from undue distress. This has subsequently been called 'indefensibly paternalistic" ${ }^{\prime 1}$ but probably represents widespread practice.

Recent interest in CPR was stimulated by the 1991 report of the Health Service Commissioner, ${ }^{13}$ who upheld a complaint from a patient's son about a DNR decision which had been made on his mother by a junior doctor. He expressed surprise that a written CPR policy seemed to be 'something of a novelty' and suggested that hospitals should develop policies. Guidelines from the British Medical Association and the Royal College of Physicians of London ${ }^{1,2}$ will help hospitals establish policies, but they do not give specific advice about discussing resuscitation with patients and relatives, or what to do if there is disagreement. Doyal and Wilsher's guidelines ${ }^{14}$ are likely to be of more practical benefit, and they recognise that (unlike the US) relatives do not have a legal right to make decisions on behalf of incompetent patients.

There have been no large British studies addressing this subject, although there have been a number of smaller ones, mostly in elderly patients. ${ }^{5-10}$ Many of these have limitations and highlight the confusion that exists among patients, their relatives, their doctors and the investigators themselves. The authors of one paper claimed, quite incorrectly, that the defence organisations advised doctors that they were always obliged to perform CPR if patients requested it. ${ }^{8}$ The defence organisations later refuted this. ${ }^{15}$

Most British studies have interviewed those who were about to be discharged from hospital or who were outpatients. ${ }^{5-8,10} \mathrm{CPR}$ decisions need to be made at the time of admission; patients who survive to discharge and are able to discuss resuscitation at that time, are not a representative group. The patients in whom decisions are most needed, of course, are those who die in hospital. Other groups where decisions may be difficult are those with dementia and those who are very ill at the time of admission, but these patients are excluded from most studies. Gunasekera $^{6}$ was only able to interview 136 of $716(19 \%)$ patients initially considered suitable for his study, and Potter et al ${ }^{9}$ attempted to interview all elderly patients on admission but excluded just over half because they were too ill or too confused. Even patients awaiting discharge are not always well enough to 


\section{Case history}

Mr DB, a 76-year-old widower, has had two previous myocardial infarctions and is admitted with unstable angina. He tells the registrar that he wants pain relief but that, if he has a cardiac arrest, he does not want resuscitation. He seems to know all about CPR and to have thought his decision through in detail. He is not depressed. The registrar says that it is the policy of the consultant that all patients on the coronary care unit should have resuscitation; he says that Mr DB shouldn't have come to hospital if he didn't want the treatment.

\section{Comment}

The registrar and the consultant are both wrong. The patient is competent and well informed and has refused the treatment; this should be clearly documented and witnessed. He has asked to have pain relief which should be given. If CPR is attempted then this could amount to assault. Other potentially life-saving treatments (eg, thrombolysis) should be discussed with him if they are considered.

\section{Box 2}

\begin{tabular}{l} 
Case history \\
Mrs SM is 83 years old and has \\
frequent admissions with \\
osteoarthritis and falls. The \\
consultant geriatrician knows her well \\
and she has told him, on several \\
previous occasions, that she thinks she \\
has lived long enough and, although \\
she is happy to have analgesics if \\
necessary, she does not want \\
treatments like 'operations and \\
intensive care and that sort of thing'. \\
She repeats this to him on the ward \\
round but refuses more detailed \\
discussions. He thinks she is \\
competent, not depressed and that \\
CPR has a small, but measurable \\
chance of success. He makes a DNR \\
decision because she has refused \\
life-prolonging treatments in general. \\
He doesn't mention this to her \\
daughters. \\
Comment \\
A DNR decision is made because of \\
poor quality of life with the implied, \\
but not explicit, consent of a \\
competent patient. The doctor could \\
have asked the patient's permission to \\
discuss this with her daughters \\
although he might have avoided this if \\
he thought that they might pressurise \\
her into agreeing to something which \\
she didn't want. He should fully \\
document the decision and reasoning. \\
\hline
\end{tabular}

Box 3 participate in discussions; about a quarter are excluded, mostly because of confusion..$^{5,10}$

Most studies have given inadequate information about CPR and then tried to determine patients' preferences. Many patients think that CPR is usually successful and, on this basis, want it for themselves. ${ }^{5,6,9,10}$ It is, of course, usually unsuccessful and Murphy and colleagues ${ }^{16}$ have demonstrated the importance of giving patients a detailed explanation of CPR, including realistic information about expected outcome, as $41 \%$ of their elderly American patients initially wanted CPR but this fell to $22 \%$ when the true outcome was explained. In a study by Liddle and colleagues ${ }^{10} 56 \%$ of patients thought that CPR was usually successful, as did $58 \%$ of patients in a study by Mead and Turnbull. ${ }^{5}$ In both studies only a general explanation of CPR was given without reference to outcome. Potter and colleagues ${ }^{9}$ specifically avoided discussing outcome, and in three other studies it is unclear what patients were told. ${ }^{6-8}$ If, in clinical practice, these investigators had tried to obtain informed consent for DNR decisions on the basis of the information given in their studies, it would almost certainly have been invalid.

Many patients would not want to be resuscitated if they had severe physical or mental impairment, especially dementia. Seventy-five per cent of Robertson's patients ${ }^{17}$ would not want CPR if they were so confused that they could not recognise family and friends, and this is confirmed in other studies. ${ }^{6,10}$

There is evidence that some British patients may prefer doctors to act in a paternalistic way; $43-65 \%$ of patients ${ }^{5,6,10}$ thought that the final decision about CPR should be the doctor's and $23-34 \%$ did not want their relatives involved in decisions. Some authors ${ }^{5,9}$ advocate discussing CPR routinely with all elderly patients on admission to hospital, even though the evidence is that this is impractical and may not be what patients want. Potter and colleagues ${ }^{9}$ had to exclude those patients who were most likely to require resuscitation decisions (the very ill and those with dementia) from discussing them. Mead and Turnbull ${ }^{5}$ support a policy of routine discussions with all competent patients, but their study does not show that this is what patients want; $35 \%$ of their patients wanted to be involved in discussions, $14 \%$ didn't and $51 \%$ didn't mind. Only $28 \%$ of Liddle's patients ${ }^{10}$ said that they wanted to discuss resuscitation at the time of hospital admission. Heller and colleagues instituted such a policy but found that their intentions were misunderstood by the patient, her relatives and the local $\mathrm{MP}$, and subsequently misrepresented by the media. ${ }^{18}$ In practice doctors discuss CPR with relatives occasionally ${ }^{7}$ but rarely with patients ${ }^{11}$ even if they profess to be strong believers in the principle.

Overall, these studies suggest that some patients want to be more involved in decisions but there may still be many who do not, or who want to leave this to their doctors, and others who do not want their relatives involved. There are practical difficulties, since those who most require resuscitation decisions are those who are also unlikely to be able to participate in discussions.

\section{Ethical and moral principles}

There are four ethical principle which govern resuscitation decisions. ${ }^{14,19}$ These are:

- respect for patient autonomy

- beneficence

- non-maleficence

- justice.

Autonomy is the ability to think, decide and then act on such thought, freely and without hindrance..$^{19}$ Respect for autonomy implies that doctors treat patients in accordance with their informed choices, even if this conflicts with the doctor's beliefs. Beneficence refers to the need to do good and non-maleficence to the need to avoid harm. These imply that treatment must be thought to be likely to succeed or that the potential benefits must outweigh the potential risks. The principle of justice refers to the doctor's duty to society as a whole. Using scarce resources to continue aggressive treatment for a terminally ill patient is potentially depriving others of the treatment.

\section{Competence and incompetence}

Patients must possess the following requirements, and demonstrate them repeatedly and consistently over time, to be legally and ethically competent to consent to treatment. ${ }^{20-22}$

- understand a simple explanation of their condition, its likely outcome and any proposed treatment 


\begin{tabular}{l} 
Case history \\
\hline Mr PM is 73 years old and \\
unconscious. He has bronchial \\
carcinoma with cerebral metastases \\
and now has pneumonia. The \\
consultant physician writes in the \\
notes that CPR would be \\
inappropriate, and explains the \\
situation to the family. However, the \\
patient's daughter has arrived from \\
America and insists that he has CPR if \\
necessary. The consultant tries to \\
persuade them that this won't help \\
but, under pressure, cancels the DNR \\
decision. When the patient has an \\
arrest the crash team is called. The \\
patient dies. \\
Comment \\
The patient was incompetent and \\
CPR was contraindicated because of \\
futility. The consultant was \\
responsible for making a DNR \\
decision in the patient's best interest. \\
The family seemed to be asking for \\
futile, life-prolonging treatment; \\
perhaps they wanted him to be kept \\
alive for relatives to travel from \\
abroad to see him? The physician \\
could have considered asking a \\
colleague to make an independent \\
clinical assessment. He should have \\
tried to explain to the family that their \\
father was dying and considered \\
asking for help from nursing \\
colleagues or the hospital chaplain. \\
He should not have cancelled the \\
DNR decision; this solved his \\
immediate problem but created \\
additional ones for the junior doctors \\
on the arrest team and the nurses. \\
\hline
\end{tabular}

Box 4
- be able to reason consistently about specific goals of treatment,

- choose to act on the basis of such reasoning,

- communicate their choice and the reason for it,

- understand the consequences of their choice.

Competence to discuss one issue does not necessarily imply competence to discuss others. ${ }^{20,21}$ Competence can be impaired as a result of a psychiatric condition (dementia, toxic confusional state) or because of a physical condition. Patients in a coma are clearly incompetent but so too may be those who are in severe pain, dyspnoeic or dehydrated.

\section{Consent and confidentiality}

\section{CONSENT TO TREATMENT}

Competent adults have the right to give or refuse consent to be examined or treated ${ }^{23}$ and must also given consent if doctors are considering withholding or withdrawing life-sustaining or life-saving treatment, which would otherwise be considered part of normal medical treatment. ${ }^{14,20}$

Consent should be informed; ${ }^{23}$ the patient must be told the likely outcome of treatment and potential risks. Consent for DNR decisions does not have to be explicit ${ }^{14}$ but can be implied by statements given repeatedly and consistently by competent patients refusing life-prolonging treatment in general. Relatives are commonly asked to sign consent forms for incompetent patients but, although this is good clinical practice, it has no basis in English Law at present. ${ }^{20}$ Doctors have an obligation to make clinical decisions on behalf of incompetent patients, in the patients' best interests. ${ }^{20}$

\section{CONFIDENTIALITY}

Doctors have an ethical and legal obligation of confidentiality to patients. ${ }^{23}$ There are circumstances when this can legitimately be broken, but doctors usually require permission from patients to disclose information about them to third parties. Incompetent patients have the same rights to confidentiality as competent ones. It is common practice in the UK for doctors to discuss patients' clinical conditions with relatives ${ }^{7,21}$ and permission to do this is often implied rather than sought explicitly. If a patient is competent then it is good practice to seek permission before discussing clinical details with relatives.

\section{Reasons for making DNR decisions}

DNR decisions are made for several reasons..$^{1,2,14,25}$

PATIENT REFUSAL

A competent, fully informed patient asks to be excluded from CPR.

\section{POOR QUALITY OF LIFE AFTER CPR}

CPR has a measurable chance of success but the quality of life after resuscitation is likely to be so poor that it is unacceptable to the patient. It is the patient's perception of their quality of life which is important, not that of their doctors or their family.

\section{FUTILITY}

The chances of the patient surviving CPR are so low that it can be regarded as futile. This is a clinical decision which does not need to involve the patient, and there is no obligation to attempt CPR in these circumstances.

Patients with disseminated malignancy, prolonged hypotension, septicaemia or severe cardiac failure virtually never survive $C P R^{11,26}$ and those with pneumonia, advanced renal impairment or who had such severe chronic illness before admission that they were homebound have a very low survival.

There is considerable debate in the US about the definition and scope of futility, and some authors argue that doctors can never be completely certain that CPR is futile. ${ }^{11,27,28}$ Doctors in the UK would probably take a more pragmatic approach. ${ }^{11}$ They may be attracted to the proposals of Blackhall ${ }^{26}$ who notes that the chances of surviving CPR in a persistent vegetative state (which many people would regard as less desirable than death) are 1-2\%, and CPR should be regarded as futile if the chances of surviving are less than this.

\section{Circumstances in which it is necessary to discuss DNR decisions with patients}

- If a competent patient indicates that he wishes to discuss CPR. ${ }^{14}$

- If a DNR decision is being considered for a competent patient on the grounds 


\section{Case history}

Mrs AR is 82 years old and has severe dementia; she doesn't recognise her family and friends. She is normally mobile but incontinent. She suffers an episode of acute pulmonary oedema on the orthopaedic ward, two weeks after surgery for fractured neck of femur. The medical registrar treat this but writes 'not for 222' in the notes. The only relatives are a daughter from her first marriage and a son from her second one; both claim to be next of kin but they don't talk to each other.

\section{Comment}

The patient is incompetent and a decision is made that CPR (which might have a reasonable chance of success) is not in her best interest, on the basis that quality of life with severe dementia is poor. The registrar should have documented the DNR decision clearly with the reasons for it, not used hospital code, and asked a consultant to ratify his decision. It seems sensible not to get involved in all but the most general discussion with the family until and unless it is possible to determine who is closest to the patient.

Box 5

\section{Case history}

Mr MS is $\mathbf{5 2}$ years old and is confined to a wheelchair following a stroke. $\mathrm{He}$ is admitted to the coronary care unit with a myocardial infarct and has a cardiac arrest, from which he is resuscitated. The nurses think that he shouldn't have further CPR. The registrar is unsure, but the following morning the consultant, after discussions with the ward sister, decides against further CPR. He does not write anything down and does not discuss it with the patient (who is alert and well orientated) but tells his wife that he is very ill and may not survive.

\section{Comment}

A DNR decision has been made for a competent patient on basis of poor quality of life without obtaining consent. The consultant is wrong not to have discussed CPR with the patient or at least asked the patient's permission to discuss it with his wife. The decision should have been clearly documented; nursing and junior medical staff may be exposed to claims of negligence for not initiating CPR unless decisions are documented. Nurses were wrong to try and guess what the patient thought about his quality of life; he should have been asked.

\section{Box 6}

of poor quality of life (and CPR is thought likely to have some chance of success). Informed consent must usually be obtained although this can be implied rather than explicit, ${ }^{20}$ and there are occasions when this general rule can be broken (see below).

\section{Circumstances when it is not necessary to discuss DNR decisions with} patients

- When a patient is judged to be incompetent by the doctor who is making the DNR decision. ${ }^{22}$

- If a DNR decision is being considered for a competent patient on the grounds of futility. In the US it is advocated that patients should be informed of decisions made on the grounds of futility. ${ }^{25}$ In the UK this is not thought to be necessary. ${ }^{4,20}$

- Occasionally it may be justified to make DNR decisions on competent patients because of poor quality of life, without obtaining consent. This is permissible when it is thought that discussing CPR with patients is likely to be detrimental to their general well-being. ${ }^{14}$

- If a competent patient indicates that they do not wish to discuss CPR.

\section{Discussing DNR decisions with patients' relatives and friends}

Discussions with relatives have a different focus from discussions with patients Doctors should consider their responsibility for maintaining confidentiality, particularly since some patients may not want their relatives involved in decisions. ${ }^{5,8}$

\section{COMPETENT PATIENTS}

Permission should always be sought from the patient to speak to relatives. ${ }^{14} \mathrm{~A}$ DNR decision is being considered on 'poor quality of life' grounds and the patient has indicated that he does not wish to discuss this, or it is thought to be detrimental to his well-being. Discussions should aim to determine the patient's views of his quality of life and life-prolonging treatment.

\section{INCOMPETENT PATIENTS}

The doctor decides about treatment in the best interest of the patient. If DNR is being considered on the basis of 'poor quality of life' then he will usually want to get a better idea of what the patients would have wanted from relatives or friends. He should also try and determine if there is an Advance Directive, which now has legal force in Britain (see below). It is usually a matter of good practice to inform relatives about an incompetent patient's progress and this is often straightforward. ${ }^{21}$ There may be occasions, however, where different family members have different views or there have been family disputes. In these circumstances the obligation remains to make a decision in the best interest of the patient and only to share information with those with whom the patient would have wanted it shared.

\section{What to tell patients about CPR}

For consent to be valid it must be fully informed. Patients should be told the likely outcome of the procedure and about any major complications.

CPR is usually unsuccessful although many doctors, including those with recent experience of it, overestimate its success. ${ }^{29}$ Survival depends on patient selection, but about $10-20 \%$ of those having CPR survive to leave hospital; most of these are still alive one year later, and long-term neurological deficits are relatively uncommon, although $1-2 \%$ survive in a persistent vegetative state..$^{11,26}$ Survival is lowest for those on general wards with chronic illness. Selected elderly patients can do as well as selected younger ones, and old age should not be used as the basis for making DNR decisions, but elderly inpatients with chronic illness probably have a less than $5 \%$ survival to discharge. ${ }^{16}$

Doctors should try and estimate success rate for the individual, mentioning the possibility of survival with neurological damage. They should ensure that patients know that if they have a cardiorespiratory arrest and do not have CPR then they will almost certainly die. ${ }^{21}$ Ideally, experienced clinicians (usually consultant ${ }^{11,14}$ ) should undertake such discussions. They should initially try to determine how much the patient wishes to get involved in decisions about life-prolonging treatments, if at all. If it is clear that the patient does not wish to discuss the issue then the doctor should seek permission to share information with a relative or friend..$^{14}$ Doctors should also discuss the implications of DNR decisions for other life-prolonging treatments. 


\section{Case history}

Mrs PM is 76 years old and house-bound with moderate dementia. She is admitted after a fall and is found to have a urinary tract infection. The geriatric registrar knows her from previous admission and she is deteriorating gradually. Her son usually speaks for the family when she's in hospital, and on this occasion he asks the registrar not to do anything to 'keep her alive unnecessarily'; he's seen CPR on the television, and he thinks that his mother wouldn't want it with her current level of confusion. The registrar writes a DNR order.

\section{Comment}

In these circumstances the chances of CPR succeeding are very small although there is no single condition which indicates futility. The patient is incompetent and the son seems to be acting in good faith, reflecting what his mother would have wanted. There are no obvious family disagreements and the registrar is right to make a DNR order. He should have this confirmed by his consultant and clearly documented and consider the implications for other treatments as well.

Box 7
Written information given to patients on admission to hospital could include a description of CPR and a statement about the hospital's resuscitation policy. ${ }^{14}$ Patients would then have the opportunity to discuss this further with medical staff if they wished or to indicate if they would find this distressing.

\section{Future developments}

The courts have recently confirmed that Advance Directives (living wills) have legal force in Britain, and doctors should consider the possibility of there being a living will when making decisions for incompetent patients. ${ }^{30}$ Recent recommendations from the Law Commission, if accepted, ${ }^{21}$ will clarify the position on Advance Directives and will provide a facility for patients to nominate another person to make healthcare decisions on their behalf in the event of incompetence. The Commission proposes that the term 'Advance Refusal' may be appropriate since it will usually refer to treatment that the patient doesn't want in certain circumstances; if a patient requests treatment in advance which is not indicated clinically then there is still no obligation to use it.

The Commission's other proposal is that the Power of Attorney legislation should be modified so that a proxy could make decisions on behalf of an incompetent adult on health matters, as well as financial ones. The proxy would be obliged to make decisions in the best interest of the patient within a framework of safeguards. There is a separate proposal that, where there is no advance refusal or nominated proxy, doctors should consult widely about what is in the best interest of the patient. It is suggested that there should be consultation with 'other people whom it would be appropriate and practicable to consult about the person's ... best interest'. This is probably what many doctors do already and the Commission avoids nominating specific relatives who should be consulted recognising that decisions have to be made 'in a world of divided families.'

\section{Conclusions}

In the future British patients and their relatives will probably want more involvement in resuscitation decisions, so doctors need a sound knowledge of the ethical and legal basis on which decisions are made. A policy of discussing CPR with all patients on admission is impractical, unnecessary and may not be what patients want. It is possible that many elderly patients might be excluded from discussions because of incompetence or because CPR is futile. Discussions will inevitably be time-consuming, should involve senior clinicians and should be detailed enough to include individual information about outcome of CPR. Written information given to all patients on admission could give details of the hospital's CPR policy and how patients can arrange to have further discussions about it. Doctors will be helped by the development of Advance Directives and should be aware that there are proposals to change the law about consulting patients' relatives.
11 Saunders J. Who's for CPR? $\mathcal{F} R$ Coll Physicians Lond 1992; 26: 254-7.

12 Bayliss RIS. Thou shalt not strive officiously. BMF 1982; 285: 1373-5.

13 Calman K. Health Service Commissioner. Annual report for 1990-1991. Resuscitation policy. PL/CMO (91)22.26 December 1992.

14 Doyal L, Wilsher D. Withholding cardiopulmonary resuscitation: proposals for formal monary resuscitation: proposals for

15 Wall JA, Palmer RN. Resuscitation and patients' views. BMF 1994; 309: 1442-3 (letter).

16 Murphy DJ, Burrows D, Santilli S, et al. The influence of the probability of survival on patients' preferences regarding cardiopulmonary resuscitation. $N$ Engl f Med 1994; 330: 545-9.

17 Robertson GS. Resuscitation and senility; a study of patients' opinions. $\mathcal{f}$ Med Ethics 1993 19: 104-7.

18 Heller A, Potter J, Sturgess I, Owen A, McCormack $P$. Resuscitation and patients' views; questioning may be misunderstood by some patients. BMF 1994; 309: 408 .

19 Gillon R. Philosophical medical ethics. Gillon R. Philosophical

20 Doyal L, Wilsher D. Withholding and withdrawing life sustaining treatment from elderly people; towards formal guidelines. BMF 1994 308: 1689-92. London: HMSO, 1995.
21 Mental incapacity. Law Commission (No 231).
22 The living will; consent to treatment at the end of life. Age Concern Institute of Gerontology and Centre of Medical Law and Ethics. London: Edward Arnold, 1988.

23 Rights and responsibilities of doctors. London: BMA, 1992.

24 Aarons EJ, Beeching NJ. Survey of 'Do Not Aarons EJ, Beeching NJ. Survey of 'Do Not Resuscitate' orders in a District
pital. BMF 1991; 304: 1504-6.

25 Tomlinson T, Brody $\mathrm{H}$. Ethics and communication in Do Not Resuscitate decisions. $N$ Engl $\mathcal{F}$ Med 1988; 318: 43-6.

26 Blackhall LJ. Must we always use CPR? N Engl f Med 1987; 317: 1281-4

27 Weijer C, Elliott C. Pulling the plug on futility. $B M F$ 1995; 310: 683-4

28 Waisel DB, Truog RD. The cardiopulmonary resuscitation not indicated order; futility revisited Ann Intern Med 1995; 122: $304-8$

29 Wagg A, Kinirons M, Stewart K. Cardiopulmonary resuscitation; doctors and nurses expect too much. $\exists R$ Coll Physicians Lond 1995; 29: too much.

30 Doyal L. Advance directives. BMf 1995; 310: $612-3$.

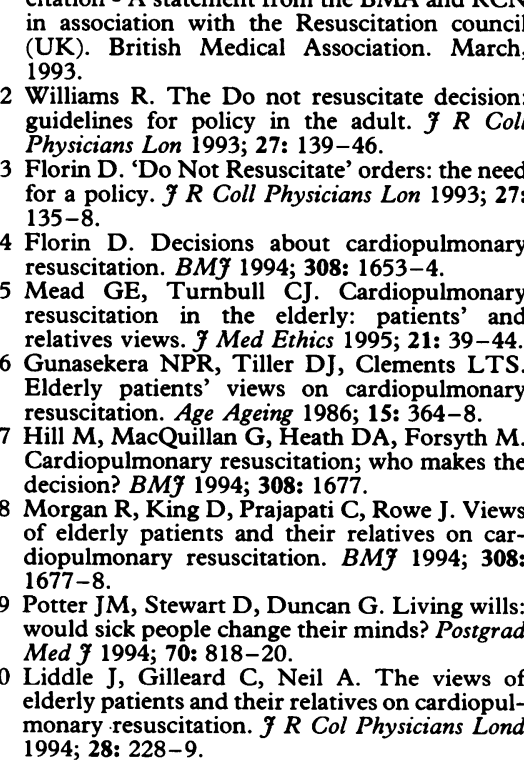

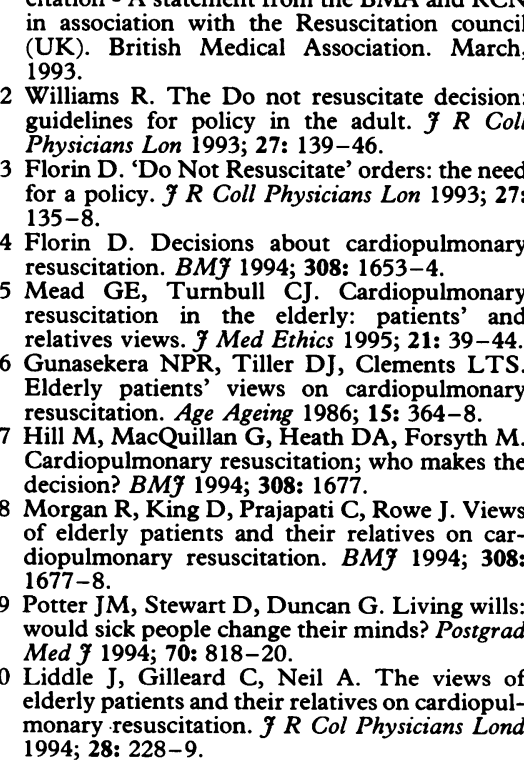

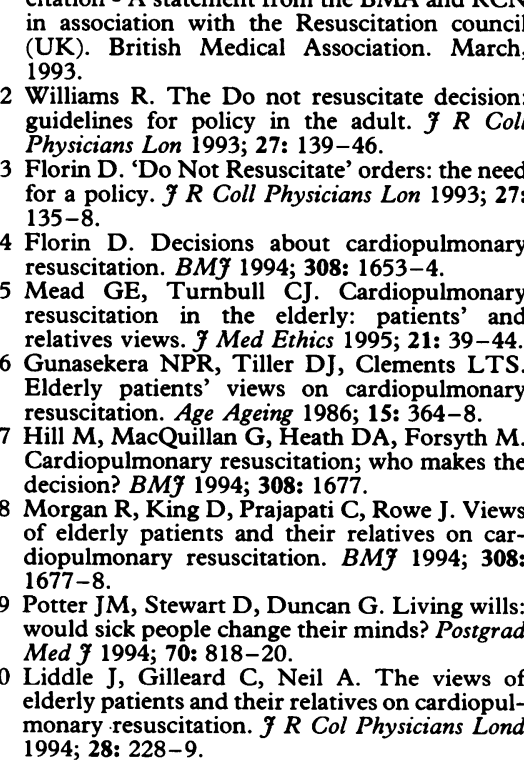

